medRxiv preprint doi: https://doi.org/10.1101/2020.12.02.20241687; this version posted December 4, 2020. The copyright holder for this preprint (which was not certified by peer review) is the author/funder, who has granted medRxiv a license to display the preprint in perpetuity.

It is made available under a CC-BY-ND 4.0 International license .

Title: Targeting multicopy prophage genes for the differential diagnosis of Lyme disease

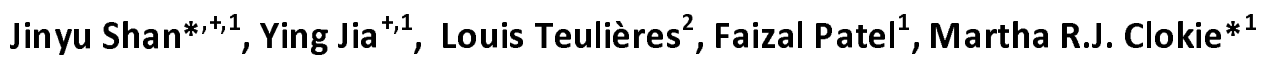

${ }^{1}$ Department of Genetics and Genome Biology, University of Leicester, Leicester, LE1 9HN, UK; ${ }^{2}$ PhelixRD Charity 230 Rue du Faubourg St Honoré, Paris, 75017, France.

${ }^{+}:$These authors contributed equally to this work

\title{
*Correspondence address:
}

Jinyu Shan, Department of Genetics and Genome Biology, University of Leicester, Leicester, LE1 $9 H N$, UK

Tel: 00441162711271

E-mail: js401@le.ac.uk

Martha R. J. Clokie, Department of Genetics and Genome Biology, University of Leicester, Leicester, LE1 9HN, UK

Tel: 00441162522959

E-mail: mrjc1@le.ac.uk

Abstract: The successful treatment of Lyme disease (LD) requires an accurate diagnostic test; however, most tests are insensitive and unspecific. To overcome these challenges, we developed and validated an internally-controlled quantitative PCR (Ter-qPCR) that targets the multicopy terminase large subunit (terL) gene encoded by prophages that are only found in LD-causing bacteria. The terL protein helps phages pack their DNA. Strikingly, the detection limit of the Ter-qPCR was analytically estimated to be 22 copies and one bacterial cell in bacteria spiked blood. Furthermore, significant quantitative differences in terms of the amount of terL detected in healthy individuals and patients with either early or late disease. Together, the data suggests that the prophage-targeting PCR has significant power to provide a differential diagnosis for LD. Prophage encoded markers are prevalent in many other pathogenic bacteria rendering this approach highly applicable to bacterial identification in general, potentially revolutionising the detection of disease.

Introduction: Lyme disease (LD) is the most common tick-born disease with more than 300, 000 cases in the US and 100, 000 cases in Europe reported annually ${ }^{1,2}$. LD is caused by a group of bacteria classified together as the Borrelia burgdorferi sensu lato (s.l.) complex, that comprises a clade of more than 20 species including B. burgdorferi sensu stricto (s.s.) which dominates in US, and B. garinii and B. afzelii which are prevalent in Europe and Asia. The LD-causing bacteria are generally transmitted to humans after they are bitten by ticks of the Ixodes family infected with LD causing Borrelia. However, recent reports have raised concerns over Borrelia transmission through blood transfusion based on observations that Borrelia can survive and circulate in the human bloodstream ${ }^{3}$.

Currently, LD diagnosis is based on the overt clinical manifestation of disease in the form of erythema migrans (EM) skin lesions, commonly known as a 'bull's-eye' rash ${ }^{4}$ and a history of tick exposure ${ }^{5}$. Although EM lesions occur in 70 to $80 \%$ of infected individuals ${ }^{5,6}$, only a third of these patients develop the classic 'bull's-eye' rash", and many other types of skin lesions can occur which are easily confused with $\mathrm{EM}^{4,8,9}$. In addition to the $\mathrm{EM}$ uncertainty, other 
common symptoms of LD such as fatigue, muscle pain, headache, and perceived cognitive dysfunction largely overlap with an array of other diseases, including other tick-borne diseases. One such example is Relapsing Fever (RF), which is caused by close relatives of the LD-causing bacteria, such as Borrelia miyamotoi ${ }^{9,10}$. The two Borrelia 'groups' responsible for LD and RF have caused great concern and clinical confusion, as they are morphologically similar and present with almost indistinguishable clinical symptoms ${ }^{11}$. Despite this, they respond to different antibiotics and treatment regimens ${ }^{12,13}$. Another example of confusion surrounding LD is the co-infection caused by Bartonella spp. This genus of bacteria is emerging as an increasingly common human infection ${ }^{14}$. Much of the controversy surrounding LD and co-infections with Bartonella and/or B. miyamotoi is due to the lack of a reliable and sensitive diagnostic method to detect and distinguish between the three groups of bacteria, the LD and RF causing Borrelia and Bartonella ${ }^{15}$. Therefore, laboratory tests to determine and distinguish between LD and co-infections play a vital role in the correct diagnosis and consequent treatment with different antibiotics.

Scientists have faced several challenges with LD detection including patients presenting with a delayed antibody response and a low number of Borrelia cells typically found in human clinical samples ${ }^{16-19}$. Serological tests for LD are also hindered by the cross-reactivity present between $\mathrm{LD}$ and $\mathrm{RF}^{16,18,20}$. Although it is particularly difficult to diagnose $\mathrm{LD}$ early, it is critical, as it is far easier to treat the disease when it is detected at an early stage ${ }^{19,21,22} 4,6,23,24$. Bacteria-targeting approaches, such as polymerase chain reaction (PCR) detecting the Borrelia chromosomal DNA, can potentially identify early LD but is relatively insensitive detecting only between $30-50 \%$ of positive cases, and is therefore deemed to have little clinical utility ${ }^{15,17,19}$. The reasons behind the poor sensitivity of the current PCR methods in Lyme diagnosis are twofold; first, the current PCRs target Borrelia genomic DNA regions that have only one copy in each bacterium, such as the bacterial 16S rRNA gene, RecA gene, and the 5S-23S intergenic regions ${ }^{15,16,25-27}$. Second, at least some Borrelia species are 'tissuebound' and are only transiently found circulating in the blood ${ }^{28}$.

In response to these diagnostic challenges, we adopted a novel approach, taking advantage of the fact that most pathogenic bacteria carry multiple complete or partial prophages (phages associated with bacteria) $^{29}$. These prophage sequences can form the bases of a template from which quantitative PCR ( $q P C R$ ) primers and probes can be designed. It is known that Borrelia carry a large number of linear and circular plasmids (comprising between 33-40\% of the Borrelia genome), among which the cp26 and cp32, and the Ip54 linear plasmid, are evolutionarily stable ${ }^{30}$. Of these paralogous plasmids, $\mathrm{cp} 32$ has been experimentally determined to be a Borrelia burgdorferi prophage thus it is highly likely that many of its homologues are also prophages ${ }^{30-34}$.

Each Borrelia species has a distinct amount of species specific variation in its prophage sequences; thus these prophages can be used as a proxy to identify the bacteria because of the tight correlation between them and the exact prophages found in each Borrelia host. As there are multiple prophages per Borrelia cell, the detectable signal is higher for prophages than bacteria. Furthermore, evidence suggests that Borrelia prophages can be released outside the Borrelia cells following encounters with stressors such as antibiotics or exposure to macrophages ${ }^{31-33,35,36}$. In this study, we confirmed that Borrelia prophages can escape from the bacterial host cell in a spontaneous manner. Taking advantage of the multicopy 
and free movement of Borrelia prophages, the approach to target prophages instead of bacteria will bypass the cryptic and tissue-bound feature that typifies human Borrelia infections ${ }^{28}$. Thus, we have a greater chance of detecting the prophages in blood even when the bacteria may not be present or present in extremely low numbers. In this sense, prophages are somewhat analogous to Borrelia 'footprints'.

Another challenge in detecting bacteria from blood samples is the successful extraction of DNA that forms the PCR target. It is well-known that DNA extraction from blood samples plays a pivotal role in the success of PCR diagnosis of bacterial infections ${ }^{37,38}$. It is also true that PCR assays may fail to amplify if bacteria are sparse, or if an inappropriate DNA extraction method was adopted that favoured an overwhelming dominance of human DNA in the final DNA product ${ }^{38-40}$. To find the most suitable DNA extraction method, three blood DNA extraction methods were applied to blood samples spiked with serial dilutions of Borrelia cells and assessed by qPCR. We determined the best DNA extraction method by assessing each sample in order to determine the highest detectable phage copy number from the Borrelia spiked blood.

In this paper we have demonstrated for the first time in Borrelia-related diagnostics that it is possible to overcome the sensitivity challenges associated with LD detection. We highlight the enormous potential of our test to discriminate between healthy volunteers, early LD, and late LD patients. We present data from a systematic and comprehensive study that validates the use of the multicopy phage terminase large subunit (terL) gene as a molecular marker for the detection of Borrelia species. The analytical performance of the terLtargeting qPCR (referred to as Ter-qPCR) was thoroughly evaluated, and the test was shown to be able to detect one single Borrelia cell from blood samples. The diagnostic potential was evaluated using a set of blood and serum samples collected from healthy volunteers and individuals who were clinically diagnosed with LD.

In summary, we demonstrate that a quantitative phage-based PCR has the potential to revolutionise the differential diagnosis of LD from blood samples. This approach of looking for induced and specific phages may be useful for a plethora of blood-borne bacterial pathogens that cause sepsis, such as Staphylococcus aureus, Escherichia coli, and Pseudomonas aeruginosa ${ }^{41}$.

\section{Results and Discussion}

\section{Multicopy, terL genes are widespread within Borrelia species}

To determine which prophage gene to use as a marker the $B$. burgdorferi B31 genome was examined and shown to carry the multicopy terL gene (NC_000948.1). This gene encodes for the terL protein which is responsible for packing phage genomes and is essential for phage survival ${ }^{42}$. The gene was found to be present on seven of the circular plasmids from the cp32 series and on three linear plasmids within B31 genome (Supplementary information 1). Blastn analysis revealed that the ter $L$ homologs are widespread in $L D$ and RF Borrelia spp., including B. miyamotoi. As summarised in Table 1, the terL homologs present in LD Borrelia species are mainly located on the cp32 plasmids with E values of zero and query cover of $100 \%$; thus, primer design specific to species was carried out. There are 13 versions of terL-bearing cp32 plasmids (cp32-1 to cp32-13), all of which are present in the $B$. 
burgdorferi spp. In contrast, B. afzelii and B. garinii encode eight and four such cp32 plasmids, respectively.

TerL homologs are also found in RF and B. miyamotoi species (E values ranging from $5 \mathrm{e}-164$ to 0.03 and a query cover ranging from $90 \%$ to $5 \%$ ). Thus, the phage terL gene appears to be a useful marker; indeed, it has previously been used as a marker to reveal the evolutionary relationships within prophages of the environmental Paraburkholderia species and lytic phages of Edwardsiella ictaluri, the causative agent of enteric septicaemia of catfish ${ }^{43,44}$. In summary, the prevalence, amount of variability in the sequence, and multicopy nature of terL suggests that it could be a suitable marker to indicate Borrelia presence. Therefore, we predicted that a qPCR targeting terL homologs will detect Borrelia species to the strain level and distinguish LD Borrelia species from RF species and B. miyamotoi.

\section{Phylogenetic analysis of the terL gene}

To determine the potential of the ter $L$ gene as a marker for specific Borrelia species, phylogenetic analyses were carried out using neighbour-joining (NJ) (Fig. 1) and likelihood (ML) methods (Supplementary Fig. 1). Both trees were concordant with each other and demonstrated three well-defined clades of LD, RF and B. miyamotoi, indicating that the terL gene is evolutionary stable and offers resolution at the Borrelia species level. As shown in Fig. 1, the ter $L$ gene resolves Borrelia into genospecies, revealing an independent sub-group of LD Borrelia species that is well-separated from the other RF Borrelia group (including $B$. miyamotoi) with statistically a significant bootstrap value.

Encouragingly, and of significant importance to diagnosis and treatment, our analyses show a well-supported resolution within the LD and RF lineages. Moreover, it is important to note that the ter $L$ phylogenetic tree largely agrees with the $16 \mathrm{~S}$ rRNA gene based Borrelia phylogeny. The only exception being that the $16 \mathrm{~S}$ tree placed B. miyamoto $i$ within the RF clade, while the ter $L$ tree places it outside both the LD and RF clades ${ }^{45-48}$. This variable phylogenetic position of $B$. miyamotoi indicates that it is distantly related to both LD and RF, but is more closely related to RF than to LD Borrelia. This detailed resolution offered by the terL gene is useful on two fronts: 1 ) it reflects the fact that the pathogenesis of $B$. miyamotoi is distinct to $\mathrm{RF}^{46,47}$; and 2) as B. miyamotoi is the only RF Borrelia that can be co-transmitted with LD Borrelia species by hard-bodied ticks ${ }^{47,49,50}$, it is really useful to have a molecular marker that can distinguish between LD and RF-causing Borrelia spp., and B. miyamotoi.

To summarise this section, the terL based phylogenetic analysis tightly correlates the Borrelia species. The phylogenetic power of the terL gene combined with the multi-copy nature suggests that it can be developed as a diagnostic marker for accurate identification of LD, and can be used to differentiate LD from related infections and co-infections such as $\mathrm{RF}$ and diseases caused by B. miyamotoi.

\section{Ter-qPCR analytical specificity, sensitivity, and efficiency}

To maximise the specificity and sensitivity of our test, we designed a set of primers and a probe to the most conserved regions of terL (to target nine out of 13 terL copies) (Fig. 2 and Supplementary information 2$)^{51}$. The specificity of the primer/probe was confirmed by Blastn and In silico' PCR (http://insilico.ehu.es/PCR/). Positive Ter-qPCR results were also obtained from all the LD Borrelia strains listed in Table 2. No positive Ter-qPCR was 
observed from B. spielmanii, or RF-causing Borrelia strains as listed in Table 2, or other nonBorrelia bacterial strains tested, along with and human DNA samples (detail in Supplementary information 3).

For clinical diagnosis and treatment, it is essential to understand the Borrelia load present in the patient, which requires absolute quantification. To develop an absolute quantification assay, we cloned the relevant ter $L$ fraction into a plasmid (Ter-plasmid) and carried out the Ter-qPCR assay with samples containing background human DNA, this in order to mimic the real clinical samples. We observed a strong linear relationship between the concentration of the Ter-plasmid and $C q\left(R^{2}=0.99\right)$ with an amplification efficiency of $99.58 \%$ (Fig. 3A). B31 DNA dilutions also displayed a robust linear association with $C q$ values $\left(R^{2}=0.999\right)$ with an amplification efficiency of $98.64 \%$ (Fig. 3B). This demonstrates the high efficiency of the TerqPCR. A close to $100 \%$ amplification efficiency from both serial dilution experiments confirmed that our standard curve assay was robust and repeatable ${ }^{52}$.

In this study, we defined the analytical limit of detection (LoD) as the lowest concentration where at least $95 \%$ of the technical replicates were positive in the Ter-qPCR ${ }^{53}$. The LoD was calculated from serial dilutions of Ter-plasmids. The proportion of Ter-qPCR positive among replicates was directly correlated with the number of plasmid copies per reaction (Supplementary Fig. 2). For example, one copy of the Ter-plasmid led to two positives out of 10 replicates, while 20 and 40 copies generated 9 and 10 positives out of 10 replicates, respectively. Probit analysis via the SPSS package was used to estimate the LoD and waS found to be 22 copies per $P C R^{54}$.

\section{DNA extraction methods matter: in vitro spiked blood samples}

To gain an insight into the potential performance of the Ter-qPCR with patients, the TerqPCR was applied to Borrelia-spiked blood samples. Consistent copy numbers from technical repeats were recovered from samples with $\geq 1$ spike-in Borrelia cell (Fig. 4A). This indicates that the Ter-qPCR can potentially detect as low as one Borrelia cell from a blood sample. In contrast, the blood sample with 0.1 of a Borrelia cell (mimicking the scenario of an extremely low level of Borrelia presence in the blood) displayed one copy number out of six repeats (Fig. 4A). It is already established that the number of Borrelia cells circulating in the blood is extremely low and is often at the lower end of the detection limit of $q P C R^{26}$. Therefore, it is common to get one PCR amplification out of technical repeats due to stochastic effect when in low concentration ${ }^{55}$. To reflect the low and random distribution nature of Borrelia cells in blood, we adopted the following rule for recording copy numbers: the replicate that did not generate a copy number (displayed as 'failed qPCR') was scored 'zero' ${ }^{55,56}$. The 'zero' Borrelia presence in blood was manifested in our later study analysing LD patient samples.

To better understand the reliability of the Ter-qPCR, simple linear regression analysis was performed. As seen in Fig. 4B, a linear association $\left(R^{2}=0.9891\right)$ was observed between the amount of spiked Borrelia cells and the resulting $\mathrm{Cq}$ values, which demonstrates that the signal intensity of Ter-qPCR correlates with the 'Borrelia load'. In other words, it appears that the Ter-qPCR can detect as low as one Borrelia per $300 \mu$ l blood, which is equivalent to 3.3 Borrelia cells per $\mathrm{ml}$ of blood. This is really promising, bearing in mind that evidence from many published studies indicates that Borrelia presence in LD patients can range from $1-100$ cells $/ \mathrm{ml}^{15,25,38,57}$. Therefore this single cell sensitivity allows the Ter-qPCR test to 
revolutionise the way Borrelia infection is diagnosed ${ }^{58}$. To put this in context, the current practice to circumvent the bottleneck of low numbers of Borrelia circulating in blood is either to culture prior to qPCR or to sample large volumes of blood to artificially increase the amount of PCR templates. Both methods have obvious drawbacks ${ }^{15,26,59}$. Intuitively, by targeting endogenous multi-copy genes, the Ter-qPCR assay offers a much more elegant and reliable way of increasing the amount of PCR template.

We initially chose the phenol method to extract DNA from blood as it is the method of choice when it comes to extracting phage $D N A^{60,61}$. Although the phenol extraction method is in many ways a gold standard, it is cumbersome. To improve the scaling of the assay, we tested commercial DNA extraction kits, such as the DNeasy Blood \& Tissue Kit (a column filtration system) and Maxwell RSC Viral Total Nucleic Acid Purification Kit (a magnetic beads-based system) to see whether they could replace the solvent-based method.

Despite a significant effort, including comparisons with bacterial chromosome-targeting $16 \mathrm{~S}$ $\mathrm{qPCR}$, the phenol extraction method outperformed the other two commercial methods. Thus, the phenol method was used throughout this study. As shown in Fig. 5, regardless of qPCR methods, the phenol approach generated a consistently higher copy number compared to the other two DNA extraction methods. The Ter-qPCR coupled with the phenol method produced significantly higher copy numbers than their counterparts of the $16 \mathrm{~S}$ qPCR from all spiked samples. Additionally, the Ter-qPCR generated robust copy numbers (three positives out of three replicates) from blood spiked with one Borrelia cell (Fig. 5), but the $16 \mathrm{~S}$ qPCR only displayed amplification once from the triplicate repeats of the same sample. The outstanding sensitivity of Ter-qPCR can also be seen from the markedly lower Cq values (therefore high amounts of PCR target) of the Ter-qPCR than that of the 165 qPCR when both qPCRs were targeting the same $B 31$ genomic DNA (Fig. 6B). The competitive advantage of targeting multicopy genes can also be seen in that the copy numbers determined by the Ter-qPCR were consistently higher than the number of spiked Borrelia, while the copy numbers established via the $16 S$ qPCR were numerically about the same as the input Borrelia number (Fig. 5).

\section{Spontaneous prophage induction provides unique discriminatory power}

It is logical that multicopy PCR targets will lead to higher sensitivity when compared to a single-copy PCR target ${ }^{62}$. We determined whether the prophage encoded genes would provide additional sensitivity to detect infections. Since some prophages can escape from their bacterial hosts either by chemical induction or spontaneous prophage induction (SPI), it is entirely possible that multiple Borrelia prophages could be released into the blood where they magnify the diagnostic signals and thus can be detected. In the case of Borrelia, terL-carrying cp32 prophages have been demonstrated to be susceptible to 1-methyl-3nitroso-nitroguanidine (MNNG) induction during in vitro culturing ${ }^{32,35,63}$. We hypothesise that Borrelia prophages are also capable of SPI which increases the chances of Borrelia prophages being induced in the human body.

To prove this SPI hypothesis, we conducted morphological and molecular studies to detect phage presence in cell-free filtrates of Borrelia cultures prior and post $36 \mathrm{~h}$ incubation. As shown in Fig. 6A, transmission electron microscope (TEM) analysis revealed particles morphologically resembling podoviruses (icosahedral heads and very short tails) ${ }^{64}$ in the 
polyethylene glycol (PEG)-purified phage fraction derived from Borrelia cultures post $36 \mathrm{~h}$ incubation. The PEG product was positive to the Ter-qPCR but negative to the Borrelia 16S qPCR (Fig. 6B). The Ter-qPCR positive result therefore indicates the presence of cp32 DNA (prophage) in the PEG product. Meanwhile, the PEG product derived from Borrelia culture prior incubation showed no phage-like particles and was negative to both the Ter-qPCR and the Borrelia $16 \mathrm{~S}$ qPCR.

Our spontaneous induction data led us to predict that the prophage-based Ter-qPCR would generate a much stronger Borrelia signal than bacteria-based qPCR, because LD Borrelia species are tissue bound and thus can only circulate in blood transiently and in very low numbers ${ }^{28}$. In contrast, under the scenario of induction, prophages are released into bloodstream, and thus can be a 'marker' indicating the presence of Borrelia, even though Borrelia cells can be hiding and not circulating in the blood. This situation of detecting free phage DNA from human blood bears some resemblance to identifying cell-free circulating DNA (cfDNA) as with cancer diagnosis ${ }^{65}$. Interestingly, the same challenge also stands in terms of the method of choice for isolating $\operatorname{cfDNA}^{66,67}$. Phenol chloroform was also highly efficient in recovering cfDNA from clinical samples ${ }^{67}$. Free phages have been discovered from a range of clinical samples, including blood ${ }^{68,69}$. Their biological significance remains to be understood. Considering the fact that metabolic active bacteria can better support phage reproduction $^{70}$, a high level of certain phages in the blood would indicate active infections of their respective bacteria, i.e. a strong ter $L$ signal would implicate active Borrelia infection. Given the fact that most pathogenic bacteria carry many inducible (including SPI) prophages, the rational of diagnosing bacteria by detecting their 'breakaway' prophages could revolutionise the current bacteria-focused paradigm of detecting bacterial infections.

\section{Performance of the Ter-qPCR against clinical samples}

As a final important validation step of this work, to determine the potential diagnostic value in a human setting, the Ter-qPCR was applied to 78 individuals belonging to three categories (early LD, late LD patients and healthy volunteers) who were diagnosed by Dr Louis Teulières ${ }^{6,23,24}$. We intended to establish the feasibility of the Ter-qPCR to detect LD. Copy numbers were determined from both blood and serum samples with three technical repeats for each sample type. The technical repeats that did not show detectable copy numbers were scored 'zero'. The raw data was presented in the Supplementary Table. Visually, there are many more 'zero' scores from serum than blood samples, and the mean and median values obtained from blood samples in each category are much higher than those from sera (Supplementary Table). The higher copy numbers determined from the whole blood as compared to the serum samples reflects Borrelia's intracellular life cycle and the fact that Ter-qPCR can detect both prophages that are inside or outside of the Borrelia cells (probably due to SPI). Therefore, whole blood is a more robust sample source from which to diagnose LD using PCR assay.

Overall, most of samples showed a low terL copy number $(<10)$, which is consistent with the current estimation of a low concentration of Borrelia circulating in the blood (Supplementary Table). It is also common to have variation among technical repeats, for example, three technical repeats of the patient No. 25 showed copy numbers of 10, 2.8, and 0 , respectively (Supplementary Table). This QPCR variability is due to the stochastic effect of having a low number of PCR templates, and has been observed in PCR detection of low level 
bacteria in blood before ${ }^{53,55}$. Markedly differences were observed in the mean copy number of early LD (2.4), and late LD (6.9), as well as healthy volunteers (0.8), which suggests a potential positive correlation between the severity of LD and the copy numbers, i.e. higher copy numbers in late LD patients, in contrast to lower copy numbers in early LD patients and healthy volunteers. Also, very encouragingly, the median values from the early (2.0) and late (1.8) LD patients are numerically higher than those of the healthy volunteers (0.7) (Supplementary Table). The fact that some healthy volunteers showed positive with copy numbers, indicates possible asymptomatic Borrelia carriage ${ }^{55}$. Most importantly, the apparent marked difference in copy numbers from the three categories is supported by statistical analysis. As shown in Fig. 7, Mann-Whitney $U$ test revealed significant differences between early LD, late LD patients and healthy volunteers in terms of ter levels determined from whole blood, which offers objective evidence to prove that LD is a fact, and that the early and late LD stages do exist. This statistics-backed difference also suggests the potential application of the Ter-qPCR to distinguish early LD from healthy asymptomatic Borrelia carrier.

We conclude that our prophage marker has the ability to differentiate between early and late LD patients. This is the first time such a sensitive and specific test has been developed for LD, and as mentioned, can be greatly beneficial in providing more effective treatments. For example, the Ter-qPCR could be used to monitor LD treatment outcomes, to indicate which treatment option may work best, and to help clinicians measure recovery. We are currently validating a terL-based assay targeting RF and B. miyamotoi, respectively, working towards a 'multiplex' PCR aiming to detect and differentiate LD Borrelia spp., RF Borrelia spp., and B. miyamoti from a single test.

Rapid and accurate detection of microbial pathogens in blood using PCR methods is promising, but hampered by the low-level presence of bacteria in circulating blood, false signals and reduced sensitivity due to unspecific amplification of human DNA. The data presented in this study demonstrates for the first time that targeting phage DNA in blood could offer a rapid diagnosis of bacterial infections and could change the paradigm in the field of PCR detection of bacteria in general.

\section{Materials and methods:}

\section{Phylogenetic analysis}

Phylogenetic analysis was constructed using the program Molecular Evolutionary Genetics Analysis (MEGA) 7 according to the previous established method ${ }^{71,72}$. Neighbour-Joining (NJ) with a maximum composite likelihood model and Maximum Likelihood (ML) based on the Tamura-Nei model analyses were conducted on a nucleotide data set of ter $L$ genes. Support for clades were estimated using a bootstrap analysis implemented in MEGA using 3, 000 replicates. The trees were rooted with phage Lambda (NC_001416) as an outgroup.

\section{Borrelia strains and cultures}

The Borrelia strains used in this study are listed in Table 1. Ten strains were provided by Professor Sven Bergström, Department of Molecular Biology, Umea University, Sweden. Seven strains were purchased from the Pasteur Institute and DSMZ (German Collection of Microorganisms and Cell Cultures $\mathrm{GmbH}$ ). Two strains were provided by the Centre for Disease Control and Prevention (CDC), USA, and two by Cecilia Hizo-Teufel from the German 
National Reference Centre for Borrelia. Borrelia cells were grown in $15 \mathrm{ml}$ Falcon ${ }^{\mathrm{TM}}$ conical tubes with a culture volume of $14 \mathrm{ml}$ of Barbour-Stoenner-Kelly (BSK) II medium with $7 \%$ rabbit serum (referred to as complete BSKII or C-BSKII) at $35^{\circ} \mathrm{C}$ without agitation as previously reported ${ }^{73}$. All culture media was filter sterilised via $0.22 \mu \mathrm{m}$ pore size filters. Visualisation and counting of Borrelia was performed using phase contrast microscopy (Ceti Magnum Trinocular) and a Fuchs Rosenthal Disposable Counting Chamber (C-Chip, NanoEnTek).

\section{DNA extraction methods}

A modified phenol-chloroform method was used to extract DNA from blood and serum samples. In brief, samples were treated with ammonium hydroxide ${ }^{74}$ followed by the classic phenol chloroform DNA extraction method ${ }^{75}$. The resulting DNA pellet was air dried for 5 min, dissolved in $40 \mu \mathrm{l} \mathrm{Tris-Cl}(10 \mathrm{mM}, \mathrm{pH} 8.5)$, and kept at $-20^{\circ} \mathrm{C}$. DNeasy Blood \& Tissue Kit and Maxwell RSC Viral Total Nucleic Acid Purification Kit were used according to the respective manufacturer instructions. The Thermo Scientific ${ }^{\mathrm{TM}}$ NanoDrop $^{\mathrm{TM}}$ One Spectrophotometer was used to measure the quantity and quality of DNA samples.

\section{The Ter-qPCR}

Primers and probe were designed using the PrimerQuest ${ }^{\circledast}$ Tool based on an alignment of phage terL genes from $13 \mathrm{cp} 32$ plasmids (cp32-1 to $\mathrm{cp} 32-13$ ) carried by $B$. burgdorferi s.I strains. The resulting Ter-qPCR amplified a $147 \mathrm{bp}$ target region $^{76}$. The fluorogenic probe was labelled with 6-carboxyfluorescein (FAM) fluorescent reporter dye at the 5?-end, an internal ZEN ${ }^{\text {TM }}$ Quencher and an lowa Black Fluorescent Quencher (IBFQ) to the 3' (5'FAM/ZEN/3'IBFQ). To rule out PCR inhibition and avoid false negatives, the Ter-qPCR was duplexed with an internal amplification control (IAC) qPCR that generated a $145 \mathrm{bp} \mathrm{PCR}$ product $^{77}$. The IAC DNA (accession number FJ357008.1) was synthesised by IDT and added to each Ter-qPCR template. The IAC probe was fluorescently labelled with the fluorescent dye of JOE at the 5?-end. The primers and probe targeting the Borrelia 16S rRNA gene were adopted from a published paper ${ }^{78}$. All the primers, probes and PrimeTime Gene Expression Master Mix were supplied by IDT.

\section{Construction of the standard DNA}

For absolute quantification, a plasmid carrying the phage terL gene fragment (named as Terplasmid) was constructed and used as the standard curve. Specifically, a pair of PCR primers was designed using Primer Blast to amplify a 721 bp region of the phage terL gene (GenBank accession NC_000948), embracing the 147-bp Ter-qPCR product region. The primers were FTer721:AGACTAAGATGCGGGCAAGA and RTer721:TTGCATCAAGAGCGTCATCA. PCRs were carried out in a LabCycler (SensoQuest $\mathrm{GmbH}$ ) in a total volume of $50 \mu \mathrm{l}$, containing 0.25 $\mathrm{mM}$ dNTPs, $3 \mathrm{mM} \mathrm{MgCl}$, $3 \mu \mathrm{M}$ primers, $50 \mathrm{ng}$ template DNA, 0.5 unit of Taq polymerase (Bioline), and $5 \mu \mathrm{l} 10 \times \mathrm{Taq}$ buffer (Bioline). Amplification conditions were: $94^{\circ} \mathrm{C}$ for $2 \mathrm{~min}, 30$ cycles of $94^{\circ} \mathrm{C}$ for $30 \mathrm{sec}, 50^{\circ} \mathrm{C}$ for $30 \mathrm{sec}, 72^{\circ} \mathrm{C}$ for $1 \mathrm{~min}$, with a final extension of $10 \mathrm{~min}$ at $72^{\circ} \mathrm{C}$. PCR products were gel-purified using a Qiagen gel extraction kit, and subjected to cloning using the $\mathrm{NEB}^{\circledR} \mathrm{PCR}$ Cloning Kit according to the manufacturer's instructions. The recombinant Ter-plasmid DNA carrying the 721-bp terL gene was purified using the Qiagen Plasmid Kit from positive clones. The concentration of the Ter-plasmid was converted into DNA copy number ${ }^{79}$. 


\section{PCR setup}

The Ter-qPCR duplexed with the IAC assay was conducted in a 20? $\mu$ l final reaction volume containing 10? $\mu \mathrm{l} 2 \mathrm{X}$ PrimeTime Master Mix, with each primer and each probe at a final concentration of 0.5 and $0.25 \mu \mathrm{M}$, respectively, 4? $\mu$ l template DNA, $2 \mu$ I IAC (200 genome copies) and nuclease-free water. Standard thermal cycling conditions (Applied Biosystems ${ }^{\mathrm{TM}}$ 7500 Fast Real-Time PCR System) were followed with an initial step of 3 ? min at $95^{\circ} \mathrm{C}$ (polymerase activation), 45 cycles of $15 \mathrm{sec}$ at 95$]^{\circ} \mathrm{C}$ (denaturation) and $1 \mathrm{~min}$ at $60^{\circ} \mathrm{C}$ (annealing/extension). The Borrelia $16 \mathrm{~S}$ qPCR setup was carried out according to the previous report $^{78}$

A non-template control (NTC), a positive control of $10 \mathrm{ng}$ B. burgdorferi B31 (labelled as B31) DNA and a standard curve made of a series of five tenfold dilutions of the Ter-plasmid DNA $\left(10^{6}-10^{2}\right)$ were included in each run. The $\mathrm{qPCR}$ result was analysed and quantified according to the standard curve using FAST7500 software v2.3. For the Ter-qPCR to be valid, the IAC signal should always be produced regardless of the presence or absence of template DNA. All samples were tested in triplicate.

\section{Analytical specificity and sensitivity}

The analytical specificity of the Ter-qPCR assay was determined using both in silico and in vitro analyses. In silico analysis of the primer and probe set was carried out using BLAST and Primer-BLAST ${ }^{80}$, and UCSC In-Silico PCR (https://genome.ucsc.edu/cgi-bin/hgPcr). For in vitro analysis, the Ter-qPCR was applied to DNA extracted from a panel of Borrelia strains that cause LD and RF (Table 1), and microbial species that have been used in the lab, including Clostridium difficile, Clostridium perfringens, Escherichia coli, Pseudomonas aeruginosa, Streptococcus pneumoniae, Staphylococcus aureus, Burkholderia thailandensis, Burkholderia pseudomallei, Haemophilus influenzae and Salmonella enterica. Additionally, human female and male DNA (Promega, G1521 and G1471), and DNA extracted using the phenol method from human whole blood (Cat\#: SER-WB10ML from Cambridge Biosciences) were also tested using the Ter-qPCR.

The analytical sensitivity of the Ter-qPCR was firstly evaluated with five tenfold dilutions of the Ter-plasmid $\left(10^{6}\right.$ to $10^{2}$ ) and B31 DNA (40 ng to $4 \mathrm{pg}$ ), respectively. Each dilution was tested with three replicates to determine the PCR linearity and amplification efficiency. The limit of detection (LoD) was then estimated by testing Ter-plasmid dilutions from 1000 to $100,80,60,40,20,10,5$, and 1 copies/PCR. Ten replicates were used for each dilution. To mimic the real situation of analysing DNA extracted from human samples, all Ter-plasmid serial dilution experiments were conducted with the presence of background human DNA $125 \mathrm{ng}$ per PCR. Probit analysis via the SPSS software was performed to calculate the LoD with $95 \%$ probability ${ }^{81}$.

\section{Spiked blood samples}

Actively growing B31 cultures in the early exponential phase (around $10^{6}$ spirochaetes $/ \mathrm{ml}$ ) was used to spike human whole blood (in duplicate) to generate a final amount of $10^{5}, 10^{4}$, $10^{3}, 10^{2}, 10,1$, and 0.1 spike-in B31 cells in $300 \mu$ l of blood. DNA extraction was carried out using the modified phenol-chloroform method. To compare the different DNA extraction methods, a subset of the B31-spiked blood samples (corresponding to $10^{3}, 10^{2}, 10$, and 1 B31 cells per $300 \mu$ l of blood) were also used for DNeasy and Maxwell DNA extractions, 
medRxiv preprint doi: https://doi.org/10.1101/2020.12.02.20241687; this version posted December 4, 2020. The copyright holder for this preprint

(which was not certified by peer review) is the author/funder, who has granted medRxiv a license to display the preprint in perpetuity.

It is made available under a CC-BY-ND 4.0 International license .

respectively. All the resulting DNAs were analysed by both the Ter-qPCR and the Borrelia $16 \mathrm{~S}$ qPCR.

\section{Spontaneous phage induction and TEM}

$14 \mathrm{ml}$ of early exponential phase, actively growing B31 cultures $\left(7 \times 10^{5}-10^{6}\right.$ cells $/ \mathrm{ml}$, dominated by free spirochaetal forms) were spun down (6000 $\mathrm{g}$ for $20 \mathrm{~min}$ ) and washed twice with sterile PBS. The resulting pellets were resuspended in $14 \mathrm{ml} \mathrm{c-BSKII}$ and incubated for $36 \mathrm{~h}$ at $35^{\circ} \mathrm{C}$. Portions of the B31 suspension prior and post $36 \mathrm{~h}$ incubation were centrifuged down, the resulting supernatants were filtered through $0.1 \mu \mathrm{m}$ pore filters. Extraction of phages from the filtrates were carried out using PEG precipitation ${ }^{61}$. The PEGpurified phage product was used for DNA extraction ${ }^{82}$ and TEM at the Core Biotechnology Services at the University of Leicester ${ }^{72}$. The resulting DNA was examined by the Ter-qPCR and the Borrelia $16 \mathrm{~S}$ qPCR assays.

\section{Ethic statement and clinical samples}

This study was carried out in accordance with protocols reviewed and approved by the Ethics Committee, Comités de protection des personnes (CPP) with investigator reference of Etude Phelix 01617 V1 and CPP reference of 17031. All patients were diagnosed by Dr Louis Teulières according to the ILADS guidelines. A total of 312 samples ( 156 whole blood and 156 serum samples) were collected from 78 individuals between April-June 2017 ( 23 healthy volunteers with no 'identifiable' LD symptoms, 13 early stage and 42 late stage LD patients). For everyone involved, two tubes of serum and two tubes of Ethylenediaminetetraacetic acid (EDTA)-treated whole blood (approximately one $\mathrm{ml}$ in each tube) were provided. Samples were provided in a coded, de-identified manner to preserve patient anonymity. Informed consent was obtained from all participants. The modified phenol chloroform DNA extraction method was applied to all the samples in a duplicate manner. Therefore, there were four DNA samples generated from one individual, two from the whole blood and two from the serum. Triplicate qPCR was applied to each DNA sample, which led to 12 Ter-qPCR data (six from whole blood, six from serum) expressed in copy numbers according to the standard curve for any one individual.

\section{Statistical analysis}

Graphpad Prism 8.4.3. was used for statistical analysis. Descriptive statistics and the D'Agostino-Pearson normality test were used to assess the data distribution. Mann-Whitney $\mathrm{U}$ tests were used to determine the significance of the difference between early, late LD patients and healthy volunteers. Furthermore, Probit analysis was carried out via the SPSS software suite (IBM SPSS Statistics 25) to estimate the LoD. The differences were not considered to be significant when the $p$-values were greater than 0.05 . Linear regressions were used to establish correlations between the serial dilution of Ter-plasmids/B31 DNAs and $\mathrm{Cq}$ values.

\section{Data availability}

The Ter-qPCR assay includes a set of oligonucleotide primers and Taqman ${ }^{\circledR}$ probes and plasmid DNA as the standard for in vitro quantitative detection of Borrelia species causing LD. All primers and probes are described in the patent application Ref. P184103.EP.01/T. Other relevant data supporting the findings of the study are available in this article and its Supplementary Information files, or from the corresponding author upon request. 


\section{Acknowledgements}

We would like to thank Dr Andrew Millard and Stacy Guiock for their help in proofreading the manuscript. We gratefully acknowledge the main funding received towards the study from the Phelix Research and Development (Phelix R\&D, 37 Langton Street, SW10 0JL London, UK, the Charity Number 1156666), the 'Gift' funding from Lymefonds, the Netherlands (ANBI-number: 858578438), and the University of Leicester Drug Discovery and Diagnostics (LD3) spring fund 2018.

\section{Author contributions}

JS and YJ contributed to this work equally. JS and MRJC co-conceived the initial idea. JS expanded the initial idea into a coherent scientific project, designed primers and probes and performed in-depth data analysis. YJ was responsible for experimentation and optimisation, data collecting and initial data interpretation. JS and YJ co-wrote the manuscript. MRJC proofread the manuscript and provided valuable comments and suggestions. FP helped with bioinformatic and phylogenetic analyses. LT carried out the ethical application, clinical samples selection and some data analysis.

\section{Competing interests}

JS, LT and MRJC are listed as inventors in the patent application No. PCT/GB2017/053323.

The remaining authors declare no competing interests.

\section{References}

1 Petrulionienè, A. et al. Epidemiology of Lyme disease in a highly endemic European zone. Medicina (Kaunas) 56, 115, doi:10.3390/medicina56030115 (2020).

2 Rebman, A. W. \& Aucott, J. N. Post-treatment Lyme disease as a model for persistent symptoms in Lyme disease. Front. Med. 7, 57-57, doi:10.3389/fmed.2020.00057 (2020).

3 Pavia, C. S. \& Plummer, M. M. Transfusion-associated Lyme disease - although unlikely, it is still a concern worth considering. Front. Microbiol. 9, 2070-2070, doi:10.3389/fmicb.2018.02070 (2018).

4 Stanek, G., Wormser, G. P., Gray, J. \& Strle, F. Lyme borreliosis. Lancet 379, 461-473 (2012).

5 Chaaya, G., Jaller-Char, J. J. \& Ali, S. K. Beyond the bull's eye: Recognizing Lyme disease. J. Fam. Pract. 65, 373-379 (2016).

6 Cruickshank, M., O'Flynn, N. \& Faust, S. N. Lyme disease: summary of NICE guidance. BMJ 12 (2018).

7 Gerstenblith, T. A. \& Stern, T. A. Lyme disease: a review of its epidemiology, evaluation, and treatment. Psychosomatics 55, 421-429, doi:10.1016/j.psym.2014.02.006 (2014).

8 Wormser, G. P. Clinical practice. Early Lyme disease. N Engl J Med 354, 2794-2801, doi:10.1056/NEJMcp061181 (2006).

9 Hatchette, T. F., Davis, I. \& Johnston, B. L. Lyme disease: clinical diagnosis and treatment. Can Commun Dis Rep 40, 194-208, doi:10.14745/ccdr.v40i11a01 (2014).

10 Aguero-Rosenfeld, M. E. \& Wormser, G. P. Lyme disease: diagnostic issues and controversies. (Expert Rev Mol Diagn. 2015 Jan;15(1):1-4. doi: 10.1586/14737159.2015.989837. Epub 2014 Dec 8.).

11 Bergström, S. \& Normark, J. Microbiological features distinguishing Lyme disease and relapsing fever spirochetes. Wien. Klin. Wochenschr. 130, 484-490, doi:10.1007/s00508-0181368-2 (2018).

12 Koetsveld, J. et al. In vitro susceptibility of the relapsing-fever spirochete Borrelia miyamotoi to antimicrobial agents. Antimicrob. Agents Chemother. 61, doi:10.1128/aac.00535-17 (2017). 
13 Prevention, C. f. D. C. a. National Center for Emerging and Zoonotic Infectious Diseases (NCEZID), Division of Vector-Borne Diseases (DVBD), $<$ https://www.cdc.gov/lyme/treatment/index.html; https://www.cdc.gov/relapsingfever/clinicians/index.html> (2019).

14 Anderson, B. E. \& Neuman, M. A. Bartonella spp. as emerging human pathogens. Clin. Microbiol. Rev. 10, 203-219 (1997).

15 Schutzer, S. E. et al. Direct diagnostic tests for Lyme disease. Clin. Infect. Dis. 68, 1052-1057 (2019).

16 Waddell, L. A. et al. The accuracy of diagnostic tests for lyme disease in humans, a systematic review and meta-analysis of north American research. PLoS One 11 (2016).

17 Moore, A., Nelson, C., Molins, C., Mead, P. \& Schriefer, M. Current guidelines, common clinical pitfalls, and future directions for laboratory diagnosis of lyme disease, United States. Emerg. Infect. Dis. 22, 1169-1177 (2016).

18 Leeflang, M. M. et al. The diagnostic accuracy of serological tests for Lyme borreliosis in Europe: a systematic review and meta-analysis. BMC Infect. Dis. 16, 016-1468 (2016).

19 Marques, A. R. Laboratory diagnosis of Lyme disease: advances and challenges. Infect. Dis. Clin. North Am. 29, 295-307 (2015).

20 Magnarelli, L. A., Anderson, J. F. \& Johnson, R. C. Cross-reactivity in serological tests for Lyme disease and other spirochetal infections. J Infect Dis 156, 183-188, doi:10.1093/infdis/156.1.183 (1987).

21 Theel, E. S., Aguero-Rosenfeld, M. E., Pritt, B., Adem, P. V. \& Wormser, G. P. Limitations and confusing aspects of diagnostic testing for neurologic Lyme disease in the United States. J. Clin. Microbiol. 57, 01406-01418 (2019).

22 van den Brand, M. et al. Evaluation of a real-time PCR assay for detection and quantification of bacterial DNA directly in blood of preterm neonates with suspected late-onset sepsis. Crit. Care 22, 018-2010 (2018).

23 Cameron, D. J., Johnson, L. B. \& Maloney, E. L. Evidence assessments and guideline recommendations in Lyme disease: the clinical management of known tick bites, erythema migrans rashes and persistent disease. Expert. Rev. Anti. Infect. Ther. 12, 1103-1135 (2014).

24 Miller, J. M. et al. A guide to utilization of the microbiology laboratory for diagnosis of infectious diseases: 2018 update by the infectious diseases society of America and the American society for microbiology. Clin. Infect. Dis. 67, e1-e94 (2018).

25 Liveris, D. et al. Comparison of five diagnostic modalities for direct detection of Borrelia burgdorferi in patients with early Lyme disease. Diagn. Microbiol. Infect. Dis. 73, 243-245 (2012).

26 Brettschneider, S., Bruckbauer, H., Klugbauer, N. \& Hofmann, H. Diagnostic value of PCR for detection of Borrelia burgdorferi in skin biopsy and urine samples from patients with skin borreliosis. J. Clin. Microbiol. 36, 2658-2665 (1998).

27 Lohr, B., Fingerle, V., Norris, D. E. \& Hunfeld, K.-P. Laboratory diagnosis of Lyme borreliosis: Current state of the art and future perspectives. Crit. Rev. Clin. Lab. Sci. 55, 219-245, doi:10.1080/10408363.2018.1450353 (2018).

28 Liang, L. et al. Rapid clearance of Borrelia burgdorferi from the blood circulation. Parasit Vectors 13, 191, doi:10.1186/s13071-020-04060-y (2020).

29 Argov, T. et al. Coordination of cohabiting phage elements supports bacteria-phage cooperation. Nat. Commun. 10, 5288, doi:10.1038/s41467-019-13296-x (2019).

30 Casjens, S. R. et al. Plasmid diversity and phylogenetic consistency in the Lyme disease agent Borrelia burgdorferi. BMC Genomics 18, 165, doi:10.1186/s12864-017-3553-5 (2017).

31 Brisson, D., Zhou, W., Jutras, B. L., Casjens, S. \& Stevenson, B. Distribution of cp32 prophages among Lyme disease-causing spirochetes and natural diversity of their lipoprotein-encoding erp loci. Applied and environmental microbiology 79, 4115-4128, doi:10.1128/aem.00817-13 (2013). 
32 Eggers, C. \& Samuels, D. S. Molecular Evidence for a New Bacteriophage of Borrelia burgdorferi. J. Bacteriol. 181, 7308-7313 (2000).

33 Grimm, D., Elias, A. F., Tilly, K. \& Rosa, P. A. Plasmid stability during in vitro propagation of Borrelia burgdorferi assessed at a clonal level. Infect. Immun. 71, 3138-3145, doi:10.1128/iai.71.6.3138-3145.2003 (2003).

34 Casjens, S. R. et al. Primordial origin and diversification of plasmids in Lyme disease agent bacteria. BMC Genom. 19, 218, doi:10.1186/s12864-018-4597-x (2018).

35 Eggers, C. H. et al. Transduction by phiBB-1, a bacteriophage of Borrelia burgdorferi. J. Bacteriol. 183, 4771-4778, doi:10.1128/jb.183.16.4771-4778.2001 (2001).

36 Casjens, S. R. et al. Genome stability of Lyme disease spirochetes: comparative genomics of Borrelia burgdorferi plasmids. PLoS One 7, 14 (2012).

37 Opota, O., Jaton, K. \& Greub, G. Microbial diagnosis of bloodstream infection: towards molecular diagnosis directly from blood. Clin. Microbiol. Infect. 21, 323-331 (2015).

38 Gosiewski, T. et al. Comparison of methods for isolation of bacterial and fungal DNA from human blood. Curr. Microbiol. 68, 149-155, doi:10.1007/s00284-013-0451-1 (2014).

39 Karumaa, S., Kärpänoja, P. \& Sarkkinen, H. PCR identification of bacteria in blood culture does not fit the daily workflow of a routine microbiology laboratory. J. Clin. Microbiol. 50, 1031-1033, doi:10.1128/JCM.01271-11 (2012).

40 Yamamoto, Y. PCR in diagnosis of infection: detection of bacteria in cerebrospinal fluids. Clin. Diagn. Lab. Immunol. 9, 508-514, doi:10.1128/cdli.9.3.508-514.2002 (2002).

41 Minasyan, H. Sepsis: mechanisms of bacterial injury to the patient. Scand. j. trauma resusc. emerg. med. 27, 19-19, doi:10.1186/s13049-019-0596-4 (2019).

42 Sun, S. et al. Structure and function of the small terminase component of the DNA packaging machine in T4-like bacteriophages. Proc. Natl. Acad. Sci. U S A 109, 817-822, doi:10.1073/pnas.1110224109 (2012).

43 Pratama, A. A., Chaib De Mares, M. \& van Elsas, J. D. Evolutionary history of bacteriophages in the genus Paraburkholderia. Front. Microbiol. 9, doi:10.3389/fmicb.2018.00835 (2018).

44 Carrias, A. et al. Comparative genomic analysis of bacteriophages specific to the channel catfish pathogen Edwardsiella ictaluri. Virol. J. 8, 6-6, doi:10.1186/1743-422X-8-6 (2011).

45 Takano, A. et al. Isolation and characterization of a novel Borrelia group of tick-borne borreliae from imported reptiles and their associated ticks. Environ. Microbiol. 12, 134-146, doi:10.1111/j.1462-2920.2009.02054.x (2010).

46 Fukunaga, M. et al. Genetic and phenotypic analysis of Borrelia miyamotoi sp. nov., isolated from the ixodid tick Ixodes persulcatus, the vector for Lyme disease in Japan. Int J Syst Bacteriol 45, 804-810 (1995).

47 Telford, S. R., 3rd et al. Borrelia miyamotoi disease: neither Lyme disease nor relapsing fever. Clin. Lab. Med. 35, 867-882 (2015).

48 Molloy, P. J. et al. Borrelia miyamotoi disease in the northeastern United States: A Case Series. Ann. Intern. Med. 163, 91-98 (2015).

49 Han, S. et al. Vertical transmission rates of Borrelia miyamotoi in Ixodes scapularis collected from white-tailed deer. Ticks Tick Borne Dis. 10, 682-689 (2019).

50 Ravagnan, S. et al. First detection of Borrelia miyamotoi in Ixodes ricinus ticks from northern Italy. Parasit Vectors 11, 130, doi:10.1186/s13071-018-2713-z (2018).

51 Kralik, P. \& Ricchi, M. A basic guide to real time PCR in microbial diagnostics: definitions, parameters, and everything. Front. Microbiol. 8 (2017).

52 Bustin, S. A. et al. The MIQE guidelines: minimum information for publication of quantitative real-time PCR experiments. Clin. Chem. 55, 611-622, doi:10.1373/clinchem.2008.112797 (2009).

53 Wei, B. et al. Development of a PCR Assay to detect low level Trypanosoma cruzi in blood specimens collected with PAXgene blood DNA tubes for clinical trials treating chagas disease. PLoS Negl. Trop. Dis. 10, e0005146, doi:10.1371/journal.pntd.0005146 (2016). 
54 Pavšič, J., Žel, J. \& Milavec, M. Assessment of the real-time PCR and different digital PCR platforms for DNA quantification. Anal. Bioanal. Chem. 408, 107-121 (2016).

55 Primus, S. et al. Efficient detection of symptomatic and asymptomatic patient samples for Babesia microti and Borrelia burgdorferi infection by multiplex qPCR. PloS one 13, e0196748e0196748, doi:10.1371/journal.pone.0196748 (2018).

56 Ellison, S. L. R., English, C. A., Burns, M. J. \& Keer, J. T. Routes to improving the reliability of low level DNA analysis using real-time PCR. BMC Biotechno/ 6, 33-33, doi:10.1186/14726750-6-33 (2006).

57 Eshoo, M. W. et al. Direct molecular detection and genotyping of Borrelia burgdorferi from whole blood of patients with early Lyme disease. PLoS One 7, e36825-e36825, doi:10.1371/journal.pone.0036825 (2012).

58 Buchanan, C. M. et al. Rapid separation of very low concentrations of bacteria from blood. J. Microbiol. Methods 139, 48-53, doi:10.1016/j.mimet.2017.05.004 (2017).

59 Tilly, K., Rosa, P. A. \& Stewart, P. E. Biology of infection with Borrelia burgdorferi. Infect. Dis. Clin. North. Am. 22, 217-v, doi:10.1016/j.idc.2007.12.013 (2008).

60 Pickard, D. J. Preparation of bacteriophage lysates and pure DNA. Methods. Mol. Biol. 502, 39, doi:10.1007/978-1-60327-565-1_1 (2009).

61 Sambrook, J. \& Russell, D. W. Molecular cloning: a laboratory manual. Vol. 1 (Cold Spring Harbor Laboratory, 2001).

62 Luo, R. F., Scahill, M. D. \& Banaei, N. Comparison of single-copy and multicopy real-time PCR targets for detection of Mycobacterium tuberculosis in paraffin-embedded tissue. J. Clin. Microbiol. 48, 2569-2570, doi:10.1128/JCM.02449-09 (2010).

63 Eggers, C. H. \& Samuels, D. S. Molecular evidence for a new bacteriophage of Borrelia burgdorferi. J. Bacteriol. 181, 7308-7313 (1999).

64 Ackermann, H. W. Bacteriophage observations and evolution. Res. Microbiol. 154, 245-251 (2003).

65 Phallen, J. et al. Direct detection of early-stage cancers using circulating tumor DNA. Sci. Transl. Med. 9, doi:10.1126/scitranslmed.aan2415 (2017).

66 Bronkhorst, A. J., Ungerer, V. \& Holdenrieder, S. The emerging role of cell-free DNA as a molecular marker for cancer management. Biomol Detect Quantif 17, 100087, doi:https://doi.org/10.1016/i.bdq.2019.100087 (2019).

67 Hufnagl, C., Stöcher, M., Moik, M., Geisberger, R. \& Greil, R. A modified phenol-chloroform extraction method for isolating circulating cell free DNA of tumor patients. J. Nucleic Acids Invest. 4, e1, doi:10.4081/jnai.2013.4282 (2013).

68 Brown-Jaque, M., Muniesa, M. \& Navarro, F. Bacteriophages in clinical samples can interfere with microbiological diagnostic tools. Sci. Rep. 6, 33000, doi:10.1038/srep33000 (2016).

69 Pacífico, C. et al. Natural occurrence of Escherichia coli-infecting bacteriophages in clinical samples. Front. Microbiol. 10, doi:10.3389/fmicb.2019.02484 (2019).

70 Burns, N., James, C. E. \& Harrison, E. Polylysogeny magnifies competitiveness of a bacterial pathogen in vivo. Evol. Appl. 8, 346-351 (2015).

71 Shan, J. et al. Temperature dependent bacteriophages of a tropical bacterial pathogen. Front. Microbiol. 5, 599-599, doi:10.3389/fmicb.2014.00599 (2014).

72 Shan, J. et al. Prophage carriage and diversity within clinically relevant strains of Clostridium difficile. Appl. Environ. Microbiol. 78, 6027-6034 (2012).

73 Zuckert, W. R. Laboratory maintenance of Borrelia burgdorferi. Curr. Protoc. Microbiol. 12 (2007).

74 Santino, I., Berlutti, F., Pantanella, F., Sessa, R. \& Del Piano, M. Detection of Borrelia burgdorferi sensu lato DNA by PCR in serum of patients with clinical symptoms of Lyme borreliosis. FEMS Microbiol. Lett. 283, 30-35, doi:10.1111/j.1574-6968.2008.01134.x (2008). 
medRxiv preprint doi: https://doi.org/10.1101/2020.12.02.20241687; this version posted December 4, 2020. The copyright holder for this preprint (which was not certified by peer review) is the author/funder, who has granted medRxiv a license to display the preprint in perpetuity.

It is made available under a CC-BY-ND 4.0 International license .

75 Sambrook, J. \& Russell, D. W. Purification of Nucleic Acids by Extraction with Phenol:Chloroform. Cold Spring Harbor Protocols 2006, pdb.prot4455, doi:10.1101/pdb.prot4455 (2006).

76 Shan, J., Clokie, M. R. \& Teulières, L. Phage-based detection of borreliosis and means therefor. (2018).

77 Deer, D. M., Lampel, K. A. \& Gonzalez-Escalona, N. A versatile internal control for use as DNA in real-time PCR and as RNA in real-time reverse transcription PCR assays. Lett. Appl.

Microbiol. 50, 366-372 (2010).

78 O'Rourke, M. et al. Quantitative detection of Borrelia burgdorferi sensu lato in erythema migrans skin lesions using internally controlled duplex real time PCR. PLoS One 8, e63968, doi:10.1371/journal.pone.0063968 (2013).

79 Staroscik, A. Calculator for determining the number of copies of a template, $<$ http://cels.uri.edu/gsc/cndna.html> (2004).

80 Ye, J. et al. Primer-BLAST: a tool to design target-specific primers for polymerase chain reaction. BMC Bioinformatics 13, 134, doi:10.1186/1471-2105-13-134 (2012).

81 Forootan, A. et al. Methods to determine limit of detection and limit of quantification in quantitative real-time PCR (qPCR). Biomol. Detect. Quantif. 12, 1-6, doi:10.1016/j.bdq.2017.04.001 (2017).

82 Sambrook, J. \& Russell, D. W. Purification of nucleic acids by extraction with phenol:chloroform. Cold Spring Harb. Protoc. 2006, pdb.prot4455, doi:10.1101/pdb.prot4455 (2006).

83 Schutzer, S. E. et al. Whole-genome sequences of thirteen isolates of Borrelia burgdorferi. J. bacteriol. 193, 1018, doi:10.1128/jb.01158-10 (2011).

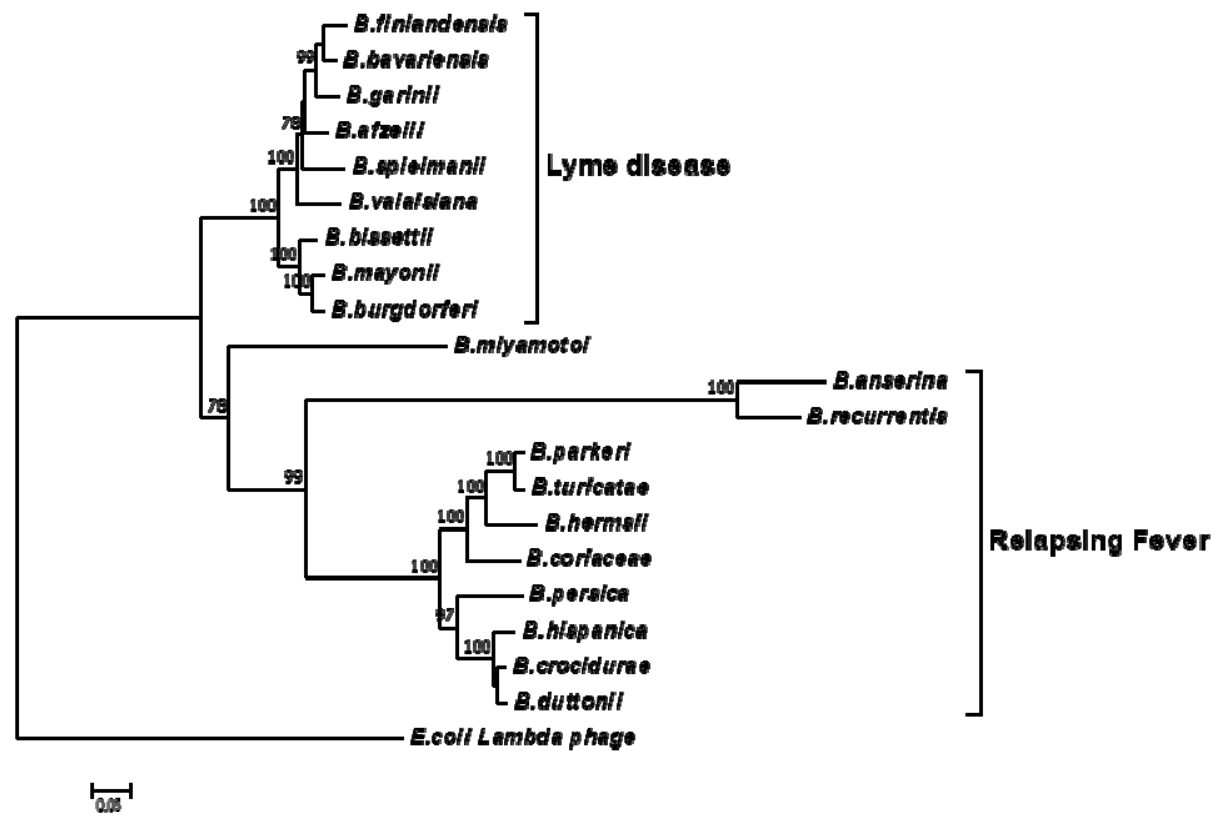

Fig. 1. A phylogenetic tree constructed based on the terL nucleotide sequence. The LD and RF Borrelia species and B. miyamotoi are separated into three well-supported clades. The Molecular Evolutionary Genetics Analysis (MEGA) package version 7 was used, and the tree was constructed via the neighbour-joining method. Scale bar represents the units of the number of base substitutions per site. Support for the clades was estimated via bootstrap analysis in MEGA with 3,000 replicates, 
medRxiv preprint doi: https://doi.org/10.1101/2020.12.02.20241687; this version posted December 4, 2020. The copyright holder for this preprint (which was not certified by peer review) is the author/funder, who has granted medRxiv a license to display the preprint in perpetuity. It is made available under a CC-BY-ND 4.0 International license.

values are indicated at the nodes (only values greater than 75 are displayed). The ter $L$ sequence from phage lambda was used as an outgroup to root the tree.

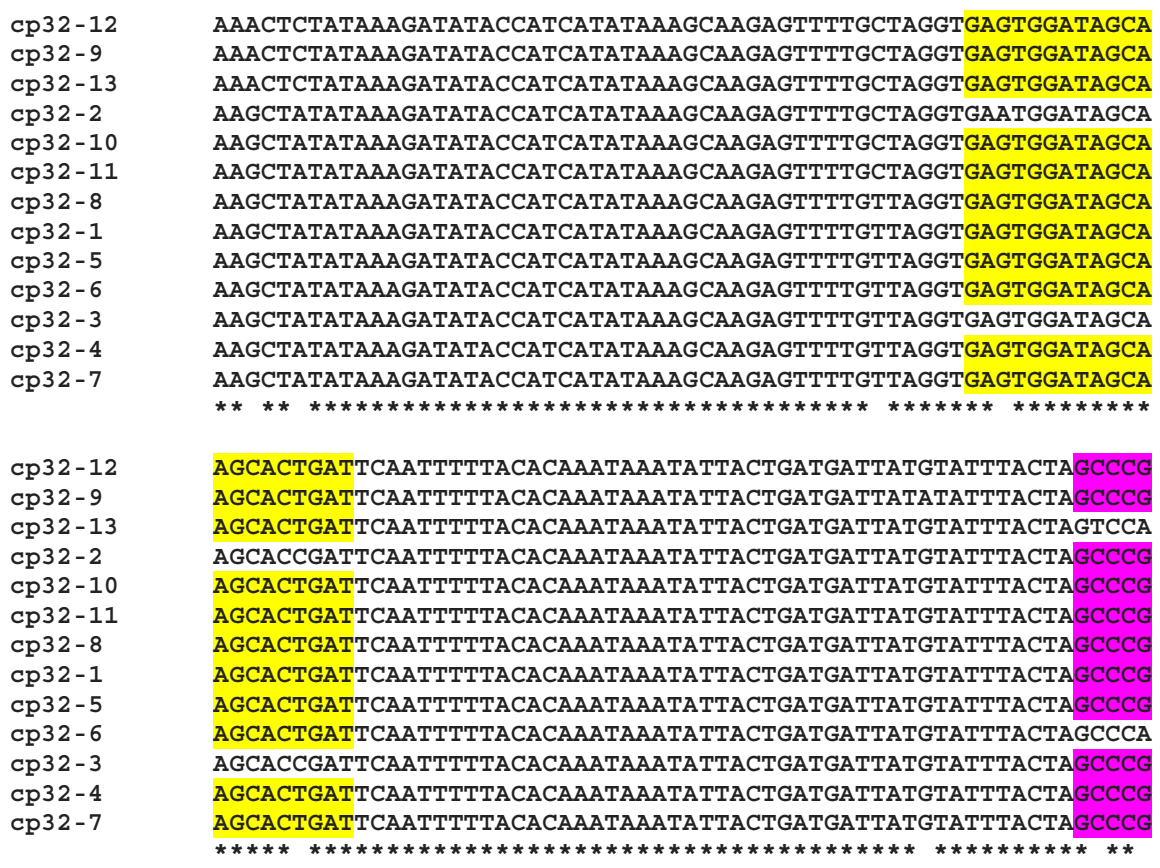

cp32-12

cp32-9

cp32-13

cp32-2

cp32-10

cp32-11

ср $32-8$

cp32-1

cp32-5

cp32-6

cp32-3

cp32-4

cp32-7

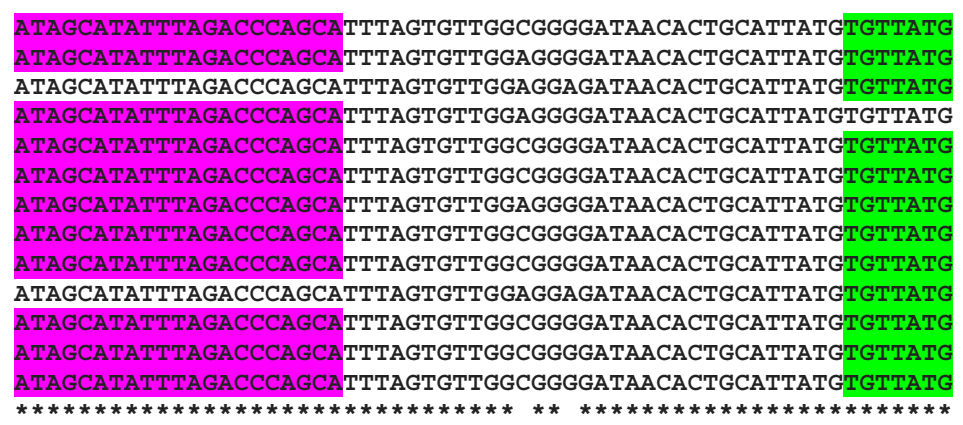

cp32-12

cp32-9

cp32-13

cp32-2

cp32-10

cp32-11

cp32-8

cp32-1

cp32-5

cp32-6

cp32-3

cp32-4

cp32-7

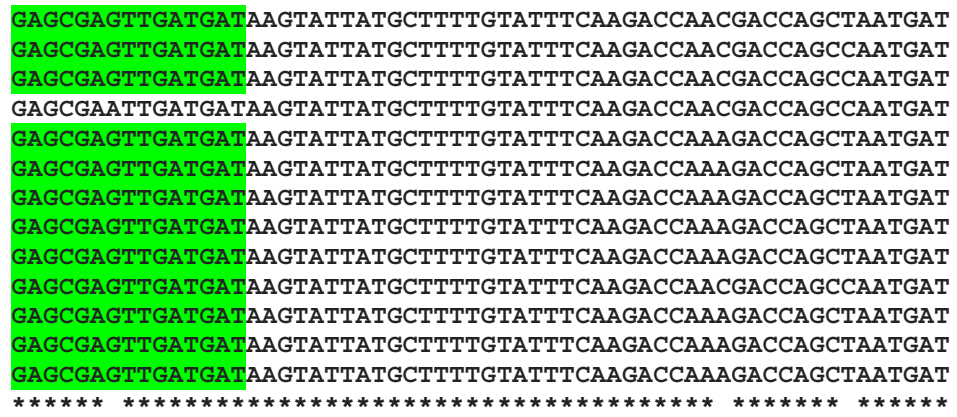

Fig. 2 Alignment of the terl gene sequence located on the 13 cp32 plasmids (cp32-1 to cp32-13). Identical nucleotides are indicated with an asterisk. Conserved regions of the forward and reverse primers, and probe are highlighted in yellow, green and purple, respectively. Identical primer/probe sequences are present in nine of the ter $L$ genes, except for those of the $c p 32-2, c p 32-3, c p 32-6$ and cp32-13 plasmids. 
A

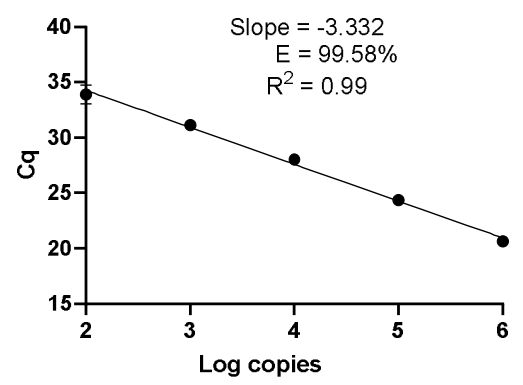

B

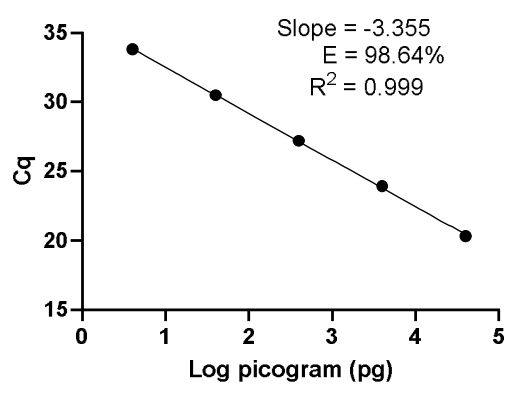

Fig. 3 The Ter-qPCR against serial dilutions of the Ter-plasmid and B. burgdorferi B31 DNA to measure the LoD and PCR efficiency: (A) Ter-plasmid and (B) B31 DNA. Cq values were plotted against the log values of serial dilutions of the Ter-plasmid and B31 DNA, respectively. Simple regression analysis was carried out using the Graphpad Prism 8.4.3 software. The slope, coefficient of correlation $\left(R^{2}\right)$ and efficiency of the reaction $(E)$ are shown. Each dot represents the average value from triplicate amplifications, along with the SD.

A

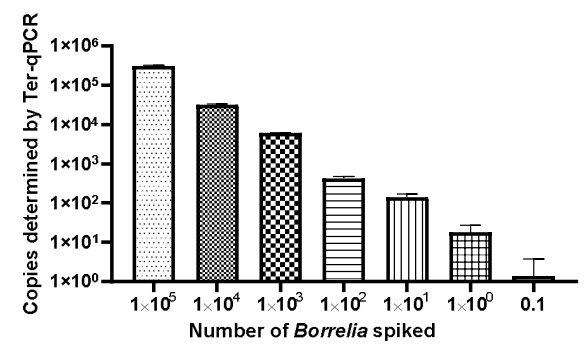

B

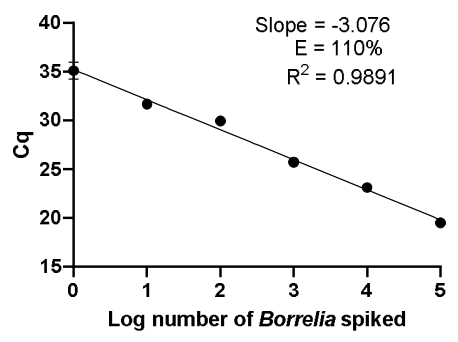

Fig. 4 Performance of the Ter-qPCR estimated by examining human blood spiked with tenfold serial dilutions of Borrelia cells $\left(10^{5}\right.$ to 0.1$)$. A: bar graph illustrating the number of spike-in Borrelia cells and the resulting copy numbers determined by the Ter-qPCR; B: Linear regression analysis between the known amount of spiked Borrelia cells and the resulting Cq values revealed a strong linear association. The slope, coefficient of correlation $\left(R^{2}\right)$ and efficiency of the reaction $(E)$ are shown. Each dot represents the average value from triplicate repeats along with SD values obtained from two independent experiments. 


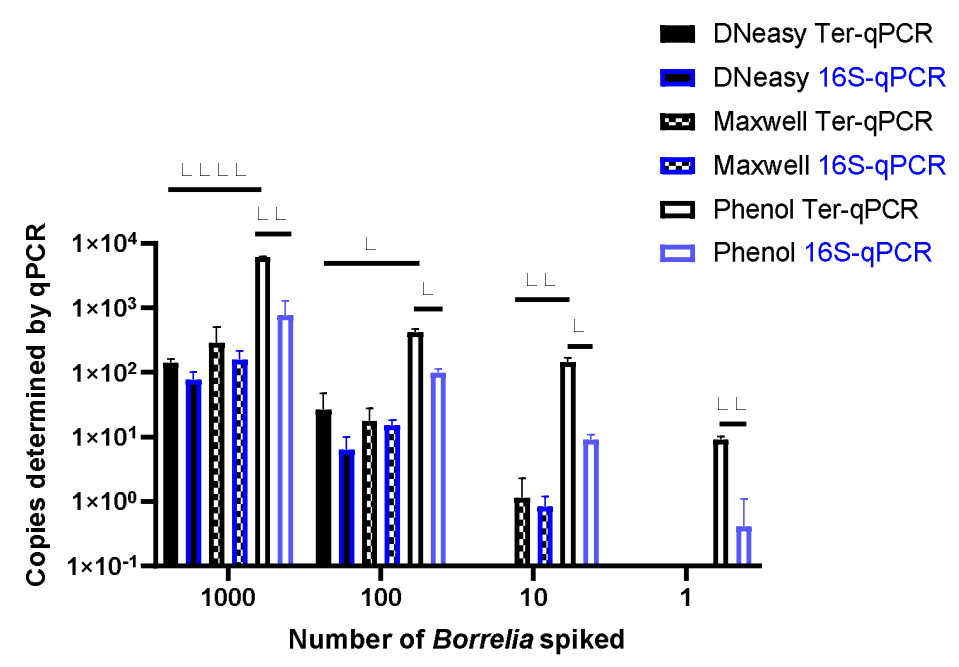

Fig. 5 The Ter-qPCR (bars with black border) and 16S qPCR (bars with blue border) against DNA extracted using three methods from human whole blood spiked with tenfold serial dilutions of Borrelia cells $\left(10^{3}\right.$ to 1$)$. The phenol method, DNeasy Blood \& Tissue Kit and the Maxwell RSC Viral Total Nucleic Acid Purification Kit were compared for DNA extraction. The Phenol method coupled with the Ter-qPCR displayed consistently and significantly higher quantitation compared to the other two methods. Copy numbers obtained from the Ter-qPCR were significantly higher than those from the $16 S$ qPCR. Values shown are the means from triplicate repeats along with SD values obtained from two independent experiments.

A

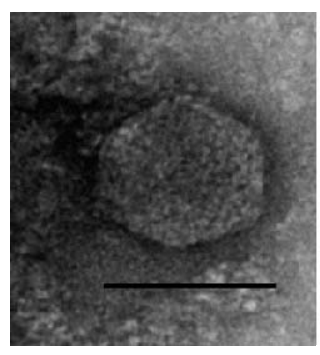

B

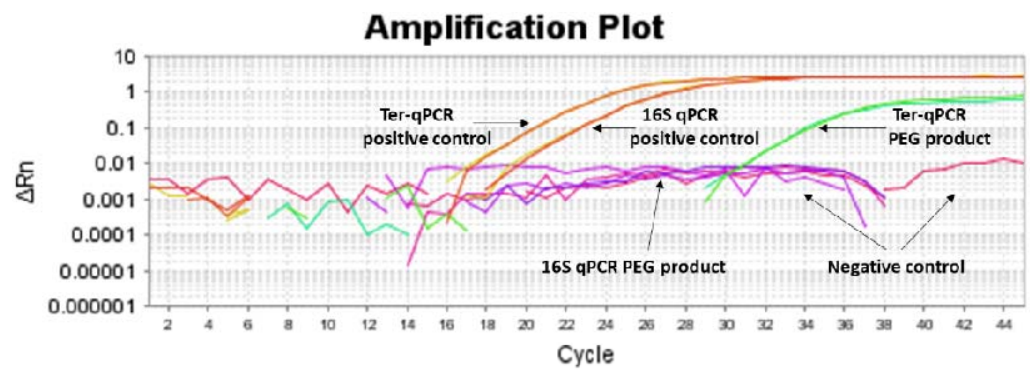

Fig. 6 Spontaneous prophage release from B. burgdorferi B31 cultures. A: Image of the phage-like particles visualised during TEM analysis of the PEG purified cell-free culture filtrates. B: DNA extracted from the PEG product tested positive during the Ter-qPCR, but negative to the $16 \mathrm{~S}$ qPCR, indicating the spontaneous release of $\mathrm{cp} 32$ prophages. $1 \mathrm{ng}$ of DNA from B31 was used as a positive control (as annotated in panel B). 


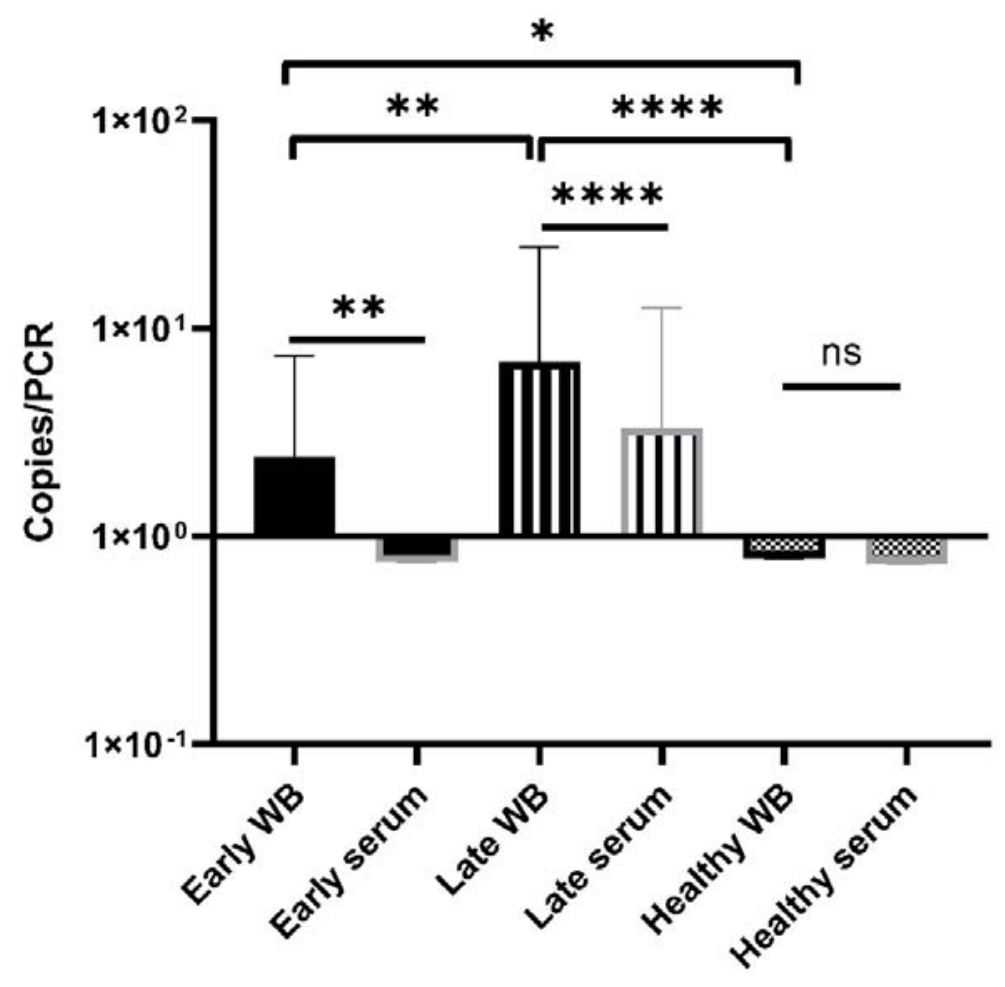

Fig. 7 Bar graph displaying the mean terL levels (with SD values) of the three respective study groups from whole blood (black border) and serum (grey border) samples. The Mann-Whitney $U$ test was used to compare differences between early LD patients, late LD patients, and healthy volunteers. The ter $L$ copy numbers obtained from the blood samples of late LD patients are significantly higher larger than those of the early LD patients and healthy volunteers, while the terL copy numbers of early LD patients are significantly higher larger than those of healthy volunteers. Statistical significance is denoted as $\mathrm{ns}(\mathrm{p}>0.05),{ }^{*}(\mathrm{p}<0.05),{ }^{* *}(\mathrm{P}<0.01),{ }^{* * *}(\mathrm{P}<0.001)$, and $* * * *$ $(\mathrm{P}<0.0001)$.

Table 1 The prevalence of the terL homologs among plasmids residing Borrelia species causing Lyme disease (smiley face and ' $x$ ' to denote presence and absence of the terL homologs, respectively)

\begin{tabular}{|c|c|c|c|c|c|c|c|c|c|}
\hline Plasmid & B. burgdorferi & B. afzelii & B. garinii & B. bissettii & B. mayonii & B. bavariensis & B. valaisiana & B. finlandensis & B. spielmanii \\
\hline cp32-1 & (:) & (:) & $x$ & $x$ & (:) & (:) & $x$ & $x$ & $x$ \\
\hline cp32-2 & (:) & $x$ & $x$ & $x$ & $x$ & $x$ & $x$ & $x$ & $x$ \\
\hline cp32-3 & (:) & (:) & (:) & (:) & (-) & (:) & $x$ & (:) & $x$ \\
\hline cp32-4 & (:) & (:) & $x$ & (:) & (-) & $x$ & $x$ & (:) & $x$ \\
\hline cp32-5 & (:) & (:) & (:) & (:) & $x$ & (:) & (:) & $x$ & $x$ \\
\hline cp32-6 & (:) & $x$ & (:) & (:) & (:) & $x$ & $x$ & $x$ & $x$ \\
\hline cp32-7 & (:) & (:) & $x$ & (:) & $x$ & (:) & $x$ & (:) & $x$ \\
\hline cp32-8 & (:) & $x$ & $x$ & $x$ & $x$ & $x$ & $x$ & $x$ & $x$ \\
\hline
\end{tabular}


medRxiv preprint doi: https://doi.org/10.1101/2020.12.02.20241687; this version posted December 4, 2020. The copyright holder for this preprint (which was not certified by peer review) is the author/funder, who has granted medRxiv a license to display the preprint in perpetuity.

\begin{tabular}{|c|c|c|c|c|c|c|c|c|c|}
\hline ср32-9 & (-) & (-) & $x$ & $x$ & $x$ & $x$ & $x$ & $x$ & $x$ \\
\hline cp32-10 & (-) & $x$ & (:) & $x$ & $x$ & $x$ & (-) & $x$ & $x$ \\
\hline cp32-11 & (i) & (i) & $x$ & (-) & $x$ & $x$ & $x$ & $x$ & $x$ \\
\hline cp32-12 & (i) & (i) & $x$ & $x$ & $x$ & $x$ & $x$ & (-) & $x$ \\
\hline cp32-13 & (-) & $x$ & $x$ & $x$ & (i) & $x$ & $x$ & $x$ & $x$ \\
\hline cp32-2-7 & $x$ & $x$ & $x$ & $x$ & $x$ & $x$ & (i) & $x$ & $x$ \\
\hline $\begin{array}{l}\text { cp32- } \\
5+1^{b}\end{array}$ & (:) & $x$ & $x$ & $x$ & $x$ & $x$ & $x$ & $x$ & $x$ \\
\hline $\mathrm{cp} 32-5-1^{\mathrm{c}}$ & (-) & $x$ & $x$ & $x$ & $x$ & $x$ & $x$ & $x$ & $x$ \\
\hline $\begin{array}{l}\text { cp32- } \\
3+10^{d}\end{array}$ & (-) & $x$ & $x$ & $x$ & $x$ & $x$ & $x$ & $x$ & $x$ \\
\hline $\mathrm{cp} 30$ & $x$ & (-) & $x$ & $x$ & $x$ & $x$ & $x$ & $x$ & $x$ \\
\hline |p17 & (-) & $x$ & $x$ & $x$ & $x$ & $x$ & $x$ & $x$ & $x$ \\
\hline cp18 & (-) & $x$ & $x$ & $x$ & $x$ & $x$ & $x$ & $x$ & $x$ \\
\hline Ip25 & $x$ & $x$ & $x$ & $x$ & $x$ & (;) & $x$ & $x$ & $x$ \\
\hline |p28-4 & $x$ & $x$ & $x$ & $x$ & $x$ & (-) & $x$ & $x$ & $x$ \\
\hline Ip54 & (-) & $x$ & $x$ & $x$ & $x$ & $x$ & (-) & (-) & (-) \\
\hline Ip56 & (i) & $x$ & $x$ & $x$ & $x$ & $x$ & $x$ & $x$ & $x$ \\
\hline Total hits & 147 & 25 & 14 & 8 & 8 & 6 & 5 & 5 & 1 \\
\hline
\end{tabular}

a. cp32-2-7 refers to $\mathrm{cp} 32-2$ and $\mathrm{cp} 32-7$ as both plasmids have the same compatibility ${ }^{30}$.

b. cp32-1+5 refers to a fusion plasmid discovered from $B$. burgdorferi JD1 that is made up of two different full-length cp32-1 and cp32-5 fused together to form a circular plasmid ${ }^{36}$.

c. $\quad \mathrm{cp32-1-5}$ is another version of $\mathrm{cp32-1-5}$ referring to the fusion of $\mathrm{cp32}-1$ and $\mathrm{cp32}-5$ into a single circular replicon ${ }^{31}$

d. cp32-3+10 refers to a fusion plasmid discovered from $B$. burgdorferi $B 31$ that is made up of two different full-length cp32-3 and cp32-10 fused together to form a circular plasmid ${ }^{36,83}$.

Table 2 Borrelia strains used in this study

\begin{tabular}{|l|l|l|l|l|}
\hline Lab number & Isolate name & Scientific name & Source & Disease \\
\hline B31 & B31 & Borrelia burgdorferi & Sven Bergström & LD \\
\hline 1 & 1120 & Borrelia duttonii & Sven Bergström & RF \\
\hline 2 & Her HS1 & Borrelia hemsii & Sven Bergström & RF \\
\hline 3 & VS185 P9 & Borrelia burgdorferi & Sven Bergström & LD \\
\hline 4 & NE218 & Borrelia valasiana & Sven Bergström & LD \\
\hline 5 & ACA1 & Borrelia afzelii & Sven Bergström & LD \\
\hline 6 & UK filtered & Borrelia burgdorferi & Sven Bergström & LD \\
\hline 7 & 190 P9 & Borrelia garinii & Sven Bergström & LD \\
\hline 8 & China23 & Borrelia burgdorferi & Sven Bergström & LD \\
\hline 9 & CA128 & Borrelia bisettii & Sven Bergström & LD \\
\hline 10 & FR64b & Borrelia miyamotoi & CDC, USA & RF \\
\hline 11 & HT31 & Borrelia miyamotoi & CDC, USA & RF \\
\hline
\end{tabular}


medRxiv preprint doi: https://doi.org/10.1101/2020.12.02.20241687; this version posted December 4, 2020. The copyright holder for this preprint (which was not certified by peer review) is the author/funder, who has granted medRxiv a license to display the preprint in perpetuity.

$$
\text { It is made available under a CC-BY-ND } 4.0 \text { International license. }
$$

\begin{tabular}{|l|l|l|l|l|}
\hline 12 & CIP 109134 & Borrelia burgdorferi & Institut Pasteur & LD \\
\hline 13 & CIP 108855T & Borrelia spielmanii & Institut Pasteur & LD \\
\hline 14 & CIP 105366T & Borrelia Iusitaniae & Institut Pasteur & LD \\
\hline 15 & DSM 21467 & Borrelia valasiana & DSMZ & LD \\
\hline 16 & DSM 10508 & Borrelia afzelii & DSMZ & LD \\
\hline 17 & DSM 10534 & Borrelia garinii & DSMZ & LD \\
\hline 18 & DSM 23469 & Borrelia bavariensis & DSMZ & LD \\
\hline 19 & Pbi & Borrelia bavariensis & Cecilia Hizo-Teufel & LD \\
\hline 20 & NT54 & Borrelia bavariensis & Cecilia Hizo-Teufel & LD \\
\hline
\end{tabular}

LD: Lyme disease; RF: Relapsing fever 